\title{
Pulling Together: Navigating Indigenisation From Within
}

\section{INTRODUCTION}

It is in my position as a visitor on the traditional and ancestral territories of the Coast and Straits Salish peoples in British Columbia, Canada, and in my role as senior manager of collaborative projects at BCcampus that I respectfully share the work created in the BCcampus Indigenization Collaborative Project (the project) and BCcampus' learning towards reconciliation. Dianne Biin, a Tsihqot'in Nation educator, whose territory is located within British Columbia (BC), managed the project. The project was led by a steering committee of Indigenous educational leaders and includes content from 30 Indigenous educators and allies across British Columbia. ${ }^{1}$ The professional learning guides produced through this project offer knowledge, experience and Indigenisation expertise to the $B C$ post-secondary education system.

This article highlights aspects of the story that emerged and my organisation's learning during the creation of these guides. As I reflect on many teachings I have received over the last several years, I aim to honour and hold space for Indigenous voices while balancing the weight and meaning of my words. Uncovering and working through my own biases and fragilities has been uncomfortable, transformative work. In the sharing of this process and our learnings at BCcampus, I continue to walk towards reconciliation, a responsibility that I believe all non-Indigenous Canadians need to own if we are to move forward in Canada.

\section{BACKGROUND}

In 2015, the Truth and Reconciliation Commission of Canada (TRC) revealed to all Canadians the devastating and lasting effects of residential schools on Indigenous peoples. Residential schools were government-sponsored religious schools established to assimilate Indigenous children into Euro-Canadian culture. From the 1870 s until 1996, over 150,000 children were removed from their families and communities and stripped of their culture, language and traditions, in a process that the TRC has referred to as cultural genocide. At these schools, children faced a multitude of abuses, traumas and injuries, and thousands of children died. ${ }^{2}$ 


\section{Pulling Together}

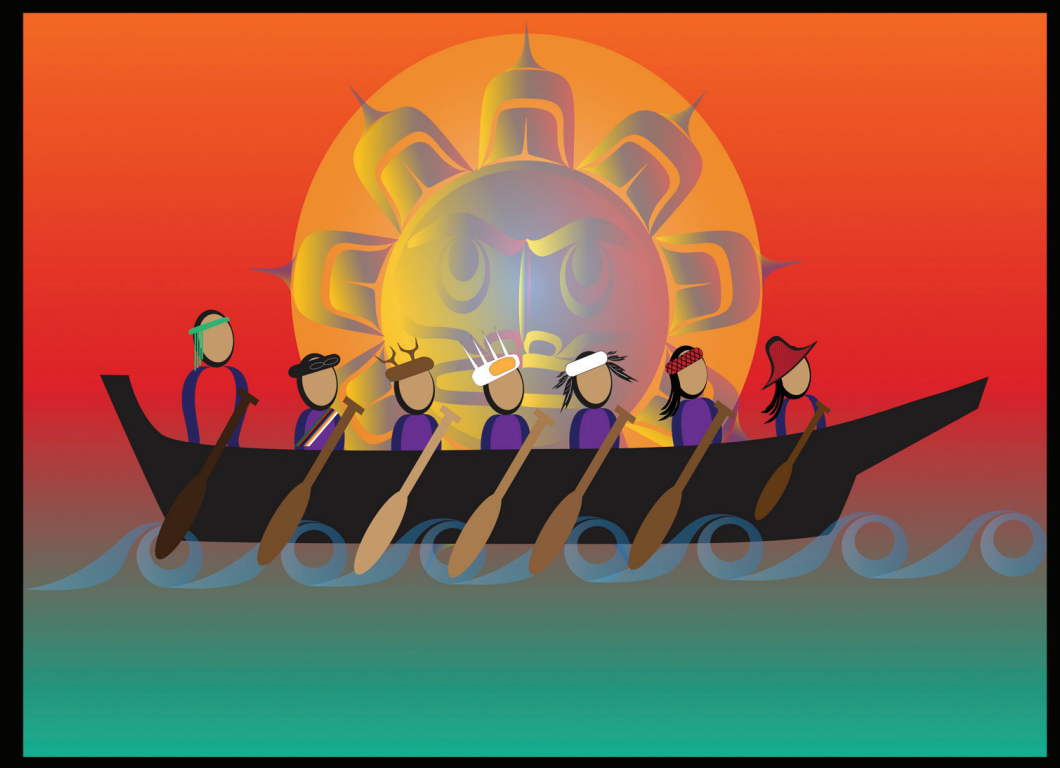

\section{A Guide for Indigenization of Post-Secondary Institutions}

\section{Professional Learning Series}

Figure 1. The cover image used on all the guides for Pulling Together: A Guide for Indigenization of Post-Secondary Institutions. A professional learning series. The cover image of the Indigenization guides is of a canoe carrying people over water from Kwakwaka'wakw artist Lou-ann Neel. The artist explains that inspiration came from an annual gathering of ocean-going canoes called Tribal Journeys. This image also tells the story of a large collaboration that resulted in a series of professional learning guides for the post-secondary sector in British Columbia, Canada. CC BY 4.0 
The TRC published the Calls to Action to redress the legacy of residential schools and advance a process of Canadian reconciliation, ${ }^{3}$ which renewed efforts within many sectors. While many post-secondary institutions were already working with Indigenous communities, the TRC's Calls to Action resulted in project funding from a variety of sources that aimed to address the Calls to Action.

During this time, between 2016 and 2018, the BCcampus Indigenization Project, funded by the British Columbia Ministry of Advanced Education, Skills and Training (Ministry), formed a collaboration between the Ministry, BCcampus and a Indigenization Project steering committee of eight Indigenous educational leaders and 30 Indigenous and ally writers representing 14 BC postsecondary education institutions.

The steering committee's goal was expressed thus: "systemic change means that the public post-secondary education system is relevant, responsive, respective, and receptive to Aboriginal learners and communities." 4 To achieve this goal, the steering committee decided to create open educational resources that would contribute to an increased awareness and understanding of Indigenous histories, cultures, perspectives and ways of knowing for those who work in postsecondary institutions.

The project charter canvas states that the incorporation of Indigenous epistemologies into professional practice will enable post-secondary institutions to develop structures and processes by which Indigenous students experience their post-secondary education in resonance with their own lives, worldviews and ambitions; support the goal, inherent in the Truth and Reconciliation Commission's Call to Action, that non-Indigenous people prepare to live well and work well alongside Indigenous peoples; and appropriately respond to social and economic development education and training needs of Indigenous nations, communities and organisations across British Columbia.

In the early phase of planning with the steering committee, members agreed that the project would produce professional learning materials to support Indigenisation efforts for five audiences in post-secondary education: leaders and administrators; teachers and instructors; frontline staff, student services and advisors; curriculum developers; and researchers. ${ }^{5}$ In addition, a foundational guide would become an integral part of the series as a first learning step for all audiences. It was envisioned that the content and approach to implementing the guides would be localised, allowing each institution to follow their own path with the Indigenous communities, families and students they serve.

During the project, a story emerged that guided our work as explained in the overview section of the guides:

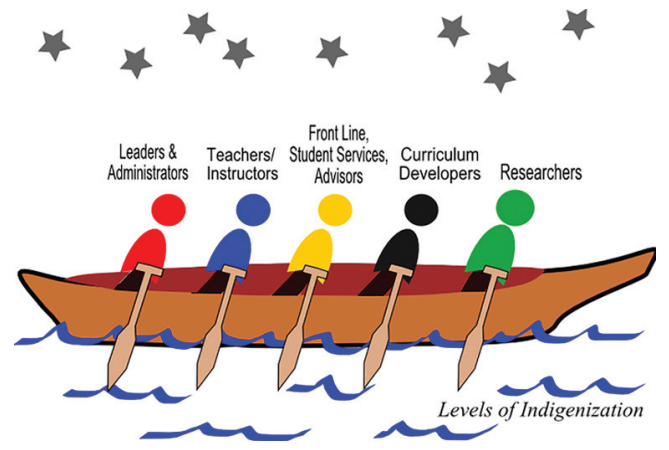

Figure 2. This image Pulling Together: A Canoe Story, 2016, emerged as an illustration of the Indigenization Project's guiding story and was developed in collaboration with the steering committee over the first year of the project. Dianne Biin, CC BY 4.0. 
The Indigenization Project can be described as an evolving story of how diverse people can journey forward in a canoe. In Indigenous methodology, stories emphasize our relationships with our environment, our communities and with each other. To stay on course, we are guided by the stars in the sky, with each star a project principle: deliver holistically, learn from one another, work together, share strengths, value collaboration, deepen the learning, engage respectfully, and learn to work in discomfort. As we look ahead, we do not forget our past. The canoe holds Indigenous Peoples and the key people in post-secondary education whose roles support, lead, and build Indigenization. Our combined strengths give us balance and the ability to steer and paddle in unison as we sit side by side. The paddles are the open resources. As we learn to pull together, we understand that our shared knowledge makes us stronger and makes us one. The perpetual motion and depth of water reflects the evolving process of Indigenization. As we learn together, we ask new questions, so we continue our journey with curiosity and optimism, always looking for new stories to share. ${ }^{6}$

\section{INDIVIDUAL AND ORGANISATIONAL PREPARATION FOR INDIGENISATION}

BCcampus has a mandate from the Ministry of Advanced Education, Skills and Training to support $\mathrm{BC}$ post-secondary institutions through open education, learning and teaching, and educational technology. The purpose of our work is to improve student success.

While BCcampus had been working with Indigenous educators and weaving Indigenous perspectives and knowledges throughout curriculum projects prior to the Indigenization Project (including the development of open source code to allow for Indigenous orthographies in a widely used open repository platform), we had not been guided by a collective organisational effort towards reconciliation until 2016. Over the last two decades of sporadically learning and working with Indigenous communities and talking with Elders, I also had not yet reflected on what reconciliation meant to me.

The Indigenization Project, like many other collaborative projects, required that space be created in the system for collaboration and co-creation of learning resources. What was uniquely antithetical about this project was that the learning resources were meant to support Indigenisation in the postsecondary system, and BCcampus had not yet embarked on leadership-led effort to Indigenise.

BCcampus was given a gift and important responsibility to work with provincial thought leaders on the creation of resources on Indigenisation that could be shared and adapted by post-secondary institutions. We were a primarily white, non-Indigenous team apprehensively discussing how to prepare for this project and take good care of the process and the learning resources that would be created.

While numerous employees had been on a journey toward reconciliation, it became a priority for leadership to provide resources, learning opportunities and space for reflection for all employees. We needed to become braver and more curious in our discussions and approach to learning. We read books by Indigenous authors, enrolled in the University of British Columbia's massive open online course "Reconciliation through Indigenous Education" ${ }^{7}$ and created an internal wiki to share what we were learning. We met in person to discuss what we had been taught about Indigenous peoples, land and history. Most of what many of us had been taught growing up was incorrect and laden with racism and harmful ideas. Through a gradual unlearning and relearning together, we researched the history of Canada on our own and through the KAIROS Blanket Exercise,${ }^{8}$ learning 
about the traditional territories of our homes, schools and offices, and the space we occupy within the colonial structures we uphold. We visited Our Living Languages at the Royal BC Museum, showcasing First Peoples' Voices in British Columbia, and marveled at the 34 Indigenous languages spoken in the exhibition. Discomfort set in as we embarked on the individual work of identifying and naming our incorrect knowledge and biases and their related actions and behaviours.

The act of gathering in a circle to talk and learn from one another on several occasions was a vulnerable and uncomfortable way of working together and hearing and seeing each other differently. Dianne Biin led BCcampus staff through the first learning circle, sharing her knowledge and discussing the emotional labour required when building and reinstating relationships with Indigenous Peoples in education. These learning circles were deeply emotional heart work, integral to leading us to a better understanding about our own and shared paths to reconciliation. Many of us knew that moving forward in a good way meant we could do the work we most valued and talked about doing, working as allies in solidarity with equity-seeking groups and, specific to this project, placing the success of Indigenous students and their families and communities at the centre of this work.

\section{PLANNING TOGETHER}

One of the first steps of the project was to meet with the steering committee and consider if the BCcampus collaborative projects model could be applied to the process. This model is built on collaborative leadership principles, which include inviting multi-sector stakeholders to steer, design and co-create open learning resources together. There was agreement to use this open model, and I welcomed the reflection and adaptation through an Indigenous lens. Notably, the once linear graphic typically used to guide projects became circular, respecting an Indigenous worldview while highlighting the iterative nature of development and consultation. The idea phase, or starting point, is placed to the right or East and the review phase is placed at the top or North. The arrow within the model demonstrates continual movement, allowing us to revisit phases as often as needed.

We discussed the attributes and tasks of collaborative work and how community consultation could be used to inform the process at each phase. Similar to other cocreation projects, the framing phase stood out for me in this project as a directional marker that is revisited and refined, incorporating learnings about the process and outputs as the story unfolded along the way.

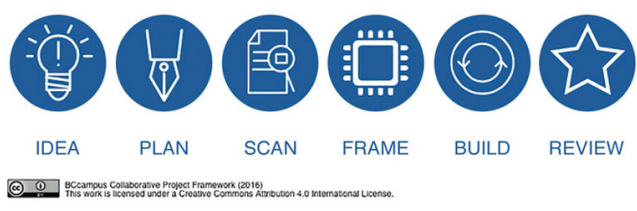

Figure 3. An open, adaptable project framework from 2015 for BCcampus collaborative projects. This framework is adapted and used for each collaborative project at BCcampus. CC BY 4.0.

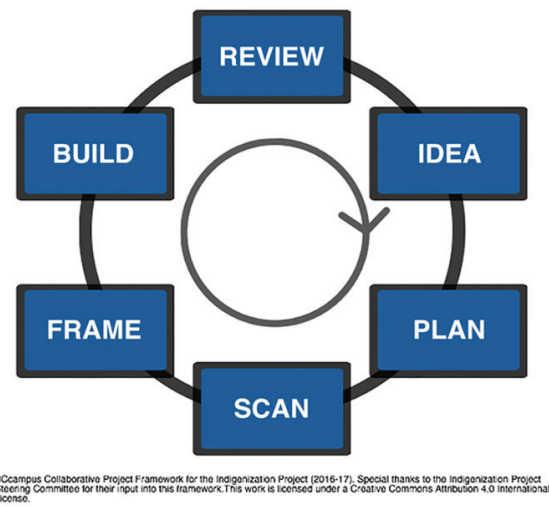

Figure 4. The adapted project framework for the Indigenization Collaborative Project of BCcampus, Indigenization Project Framework, CC BY 4.0. 


\begin{tabular}{|c|c|c|c|}
\hline \multirow{2}{*}{$\begin{array}{l}\text { Level } \\
\text { Fear of the unknown }\end{array}$} & \multicolumn{3}{|c|}{ Barriers, Challenges, Fragilities } \\
\hline & $\begin{array}{l}\text { "What are you trying to } \\
\text { take from me?" } \\
\text { "I don't know what I } \\
\text { don't know" }\end{array}$ & $\begin{array}{l}\text { "I'm helpless" } \\
\text { Unsure of who to } \\
\text { engage }\end{array}$ & $\begin{array}{l}\text { "We don't have enough } \\
\text { to share" } \\
\text { "I don't want to } \\
\text { appropriate" }\end{array}$ \\
\hline Fear of change & $\begin{array}{l}\text { "Yes, but..." (passive- } \\
\text { aggressive behaviour) } \\
\text { “I don't know who to } \\
\text { talk to and how to } \\
\text { set up Indigenous } \\
\text { research" }\end{array}$ & $\begin{array}{l}\text { Vicarious trauma } \\
\text { "I'm afraid of taking } \\
\text { away or reducing } \\
\text { needlessly” }\end{array}$ & $\begin{array}{l}\text { "I don't have time for } \\
\text { this, can you (as the } \\
\text { Indigenous expert) do } \\
\text { this?" }\end{array}$ \\
\hline $\begin{array}{l}\text { Fear of losing control } \\
\text { and power }\end{array}$ & $\begin{array}{l}\text { Racism of lower } \\
\text { expectations } \\
\text { No personal buy-in: “I } \\
\text { know, but I don't care" }\end{array}$ & $\begin{array}{l}\text { "Indigenous knowledge } \\
\text { isn't scientific" }\end{array}$ & $\begin{array}{l}\text { "We cannot change } \\
\text { legislation" } \\
\text { "New age" } \\
\text { appropriation viewpoint }\end{array}$ \\
\hline Resisting practice & $\begin{array}{l}\text { "We can't get funding } \\
\text { for what programming } \\
\text { is needed" } \\
\text { Involvement if there } \\
\text { is money attached: } \\
\text { "Where's the money? } \\
\text { No money, no } \\
\text { movement" }\end{array}$ & $\begin{array}{l}\text { Diversity can be } \\
\text { confusing so pan- } \\
\text { Indian approach } \\
\text { desired: "You're too } \\
\text { exotic" } \\
\text { All Indigenous } \\
\text { work must be done } \\
\text { by Indigenous } \\
\text { employee(s) (even } \\
\text { when it means } \\
\text { completely overworking } \\
\text { Indigenous employees) }\end{array}$ & $\begin{array}{l}\text { "We don't have enough } \\
\text { resources" and "this } \\
\text { is not part of my core } \\
\text { funding" }\end{array}$ \\
\hline Resisting process & $\begin{array}{l}\text { Checklist mentality: } \\
\text { "Done, now let's move } \\
\text { on" } \\
\text { "There are union } \\
\text { barriers to hiring } \\
\text { Indigenous employees } \\
\text { and doing community- } \\
\text { based work" }\end{array}$ & $\begin{array}{l}\text { "I have academic } \\
\text { freedom" } \\
\text { Underfunding } \\
\text { Indigenous education }\end{array}$ & $\begin{array}{l}\text { "Industry standards } \\
\text { don't allow me } \\
\text { any flexibility in } \\
\text { programing, content } \\
\text { and delivery" }\end{array}$ \\
\hline $\begin{array}{l}\text { Rejecting and } \\
\text { asserting control }\end{array}$ & $\begin{array}{l}\text { "l'd rather debate than } \\
\text { negotiate" and "there } \\
\text { are limitations to } \\
\text { program length" } \\
\text { "What is authentic } \\
\text { Indigenous } \\
\text { knowledge?" }\end{array}$ & $\begin{array}{l}\text { Demanding constant } \\
\text { validation of identity } \\
\text { and Indigeneity: “Are } \\
\text { you really Métis, } \\
\text { status, non-status, } \\
\text { Inuit?" } \\
\text { Lateral violence }\end{array}$ & $\begin{array}{l}\text { Industry involvement } \\
\text { necessary: "We cannot } \\
\text { do this ourselves" }\end{array}$ \\
\hline
\end{tabular}

Table 1. Levels of Indigenizing Working Model ${ }^{11}$ 
After the collaborative consultation of the environmental scan ${ }^{9}$ had provided additional evidence that there was a gap in professional learning resources for the five audiences identified by the steering committee, the committee began to work on the framing phase of the project, focusing on the development of audience profiles. Janice Simcoe, director of Eyēê Sqâ'lewen at Camosun College and steering committee co-chair, offered to share an Indigenised integral model. This model is based on Ken Wilber's integral quadrant theory and Simcoe's scholarship and collaboration with the Aboriginal Advisory Council and Aboriginal Nations Education Department of School District 61 on Vancouver Island, BC.

\section{Indigenized Integral Model}

\begin{tabular}{|c|c|c|} 
Intention \\
Balue, belief, motivation, \\
identity
\end{tabular}

Figure 5. Indigenized Integral Quadrant Model, 2017. The Indigenized Integral Quadrant Model was used to define audience profiles for the learning series. The full model includes Indigenized behaviours and intentions for each of the five post-secondary audiences for the series. Janice Simcoe, CC BY-NC. 
The steering committee applied this model to develop desired Indigenised intentions and behaviours, or the beliefs and actions relating to four elements found in human beings and human activities for each of the five audiences. ${ }^{10}$ This framework positions students in the centre and recognises that learning and openness to learning can occur in one or more quadrants: intention, behaviour, community and systems fit.

An example of Indigenised behaviours in the 'raven' quadrant for leaders and administrators includes respecting primacy of place and presence in language, ceremony and protocols; participating respectfully in Indigenous events; taking responsibility for learning and modelling culturally appropriate practice; resourcing teaching and learning centres so Indigenous ways of knowing and doing are incorporated; supporting and resourcing Indigenous research capacity and practices; and recognising, validating and resourcing Indigenous approaches to engagement, including community-based programming and learning, researching and student service functions.

Working together on the audience profiles, the story and framing of the Pulling Together guides developed further. The steering committee identified levels of Indigenising, and these appear as water layers that the paddlers navigated on the journey to Indigenising the institution. It is here where we recognise the barriers, challenges and fragilities that must be overcome on the learning journey and that manifest in statements and questions ranging from "I don't know what I don't know" and "Indigenous knowledge is not scientific" to "Are you really Métis, status, non-status, Inuit?" See Table 1 Levels of Indigenizing Working Model

When sharing this content, Biin anecdotally noted that this model reaffirmed the experiences of post-secondary Indigenous faculty and staff, and I noted that it had been challenging for nonIndigenous faculty and staff. This part of the story carries with it difficult and complex feelings and behaviours on a continuum that includes fear of the unknown, fear of change, fear of losing control and power, resisting practice, resisting process and rejecting and asserting control. This working model gives language to identify where resistance may exist with Indigenisation efforts. The example phrases identify dominant discourse, and in them one can hear discomfort, fear and avoidance. During three separate conversations with non-Indigenous educators, we discussed and recognised phrases we had used in the past. This unexpected and valuable output was given room to emerge during the project life cycle, even though it was not listed as a deliverable. During a project, it is in this undefined space where I see the intrinsic value of collaborative leadership and the co-creation process.

\section{NAVIGATING KNOWLEDGE OWNERSHIP AT AN EARLY STAGE}

The six professional learning guides were created by teams of Indigenous and ally educators with the support of the project manager Dianne Biin. While the Ministry would normally assume that intellectual property is assigned to the government on sponsored projects that result in provincial curricular resources, BCcampus proposed early on that the authors collectively retain intellectual property as knowledge-holders. This approach was key to the success of the project, as it honoured relationships and the gift of knowledge sharing, and addressed any expectation of knowledge ownership by the funder at an early stage.

During the project, Biin and I had unexpectedly found ourselves in a meeting about knowledge ownership with a school district executive, who presumed that ownership would always be 
assumed by the contract-holder or organisation that assembled the committee and that Indigenous committee members should relinquish their intellectual property on joining the committee. During this experience, I was able to practice a nascent ability to identify and address dominant traits of our colonial system, one that readily appropriates knowledge and resources. At BCcampus, our committees have set terms of reference, and these are always reviewed with committee members to ensure that they reflect the intentions and expectations of members as much as they reflect the intentions and expectations of BCcampus. The sharing of knowledge is a generous offering to be met with respect and viewed as an opportunity to build a reciprocal relationship with the knowledge-holder.

\section{WHERE OPEN AND INDIGENOUS PERSPECTIVES CONVERGE}

BCcampus works in open education policy, and applying Creative Commons licences is typical practice for both our processes and outputs. It was important throughout the project to check my assumptions about how and if an open licence would align with the resulting resources and the type of knowledge shared. ${ }^{12}$. We discussed the attributes of each Creative Commons licence with the steering committee and writers. Together, the groups identified a licence to allow for adaptation or localisation and prohibit the commercialisation of materials. The licence used for the guides, unless otherwise noted, is a Creative Commons Attribution-NonCommerical 4.0 International licence.

Considering a Creative Commons licence without the NonCommercial designation sparked discussions about historic appropriation of Indigenous resources, land, knowledges and art, and confirmed the preference to ensure that the materials could not be packaged up and sold for a profit. As well, by not choosing the ShareAlike licence, institutions would have the option to localise the material and incorporate knowledge and language(s) that may be specific to and appropriate for the Indigenous communities they serve, without the requirement to share such material back to the larger open community.

During the lifecycle of this project, staff at BCcampus began to ask questions about how Indigenous and open pedagogies diverge and converge. Identifying where these perspectives meet in the project, Biin, inspired by an open education keynote address from Kwakwaka'wakw scholar and project committee member, Kory Wilson, placed the Rs of Indigenous perspectives: respect, relevancy, responsibility, reciprocity and relationships next to the Rs of open source: retain, reuse, revise, remix and redistribute. Using a Venn diagram, she located a convergence between the perspectives as represented in this project. The convergence includes weaving knowledge and perspectives, incorporating Indigenous and ally scholarship, and learning through storytelling and promising practice.

\section{BUILDING THROUGH A CIRCULAR APPROACH}

The cycle that occurred in the build phase of the project followed a path of iterative writing, consultation, content development in Pressbooks (the online book management system we used) and content review and refinement for each of the six guides. The process of sharing, gathering and finalising knowledge for the resources was iterative, with teams for each guide creating partial or full content and providing it to the project manager, who reviewed and revised and then shared the content with the steering committee for their review. The content then went back to the project manager for further refinement and editing before the content was input into Pressbooks. 
Historically used linear models do not illustrate this development cycle accurately. To capture and share this approach with the lens applied earlier in the project, I designed the graphic below (Figure 6). In the past, I would have described this departure from a linear approach as messy or chaotic to project managers, but I now acknowledge that this description does not appreciate or support the inherently circular nature of phases within the project life cycle.

The final outcome of the Indigenization Project was the creation of six online Pulling Together Indigenization Guides. The Foundations Guide is intended as the first step in learning about Indigenous Peoples of Canada, territorial acknowledgement, colonisation and decolonisation. The five other guides were created for specific audiences and allow readers to delve deeper into content that aligns with their role at the institution.

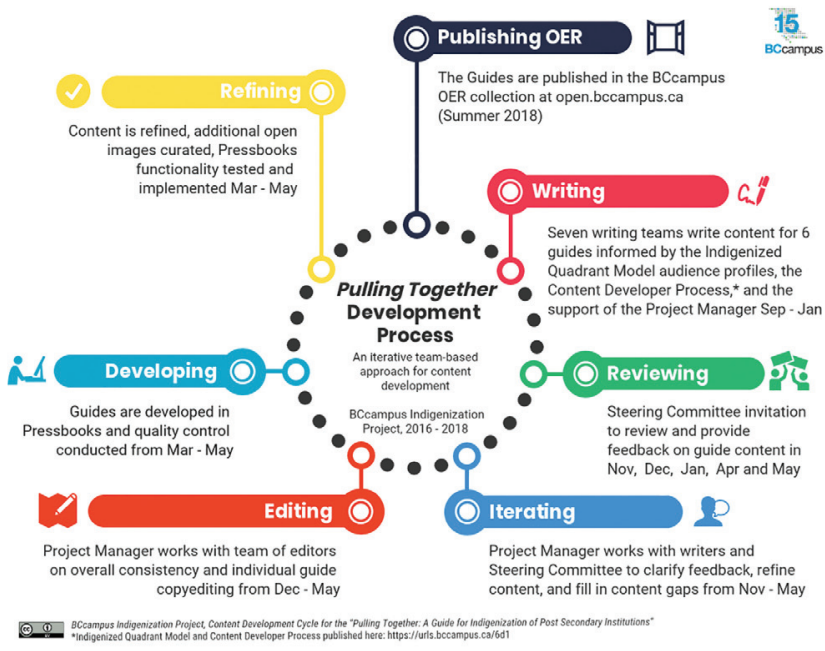

Figure 6. Indigenization Project Pulling Together development process. A diagram showing the iterative, circular approach during the build phase of the project. BCcampus, CC BY 4.0.

- The Leaders and Administrators Guide follows Indigenisation through the lens of a journey, including stages of preparing, boat launch, paddling, discovering, gathering, bringing home and sharing.

- The Teachers and Instructors Guide focuses on locating self and practice, exploring Indigenous worldviews and pedagogies, ethical approach and relational protocols, and building on Indigenised practice.

- The Curriculum Developers Guide explores Indigenisation, meaningful integration of Indigenous epistemologies and pedagogies, engaging with Indigenous communities, incorporating diverse sources of Indigenous knowledge, developing awareness of one's own role in Indigenisation and reconciliation, and promoting systemic change.

- The Front-Line Staff, Student Services, and Advisors Guide covers decolonisation, Indigenisation and reconciliation; how to support Indigenous students; understanding Indigenous worldview values to better understand Indigenous students; and moving toward an Indigenised student services.

- The Researchers Guide includes ways to Indigenise research, ethnical practices, and reciprocal research and practice. This guide has not yet been released. 


\section{REFLECTION}

The guides are living resources that can grow and change over time to support new, renewed or ongoing efforts to support Indigenisation at post-secondary institutions.

Stories of use and adaption of the guides have been shared with BCcampus. We have learned that the guides are being used in the post-secondary, not-for-profit and government sectors for organised professional learning, individual learning, to adapt curriculum and as course textbooks.

Formal research on how the learning resources are being used has not been completed by BCcampus and is outside the scope of the project. However, statistics have been compiled on unique visits and downloads between 1 September 2018 and 16 March 2019, as outlined in Table 2 below.

\begin{tabular}{|l|l|l|}
\hline Guide Name & Visits & Downloads \\
\hline Pulling Together: Foundations Guide & 6131 & 673 \\
\hline $\begin{array}{l}\text { Pulling Together: A Guide for Front-Line Staff, Student } \\
\text { Services, and Advisors }\end{array}$ & 3957 & 642 \\
\hline Pulling Together: A Guide for Leaders and Administrators & 1016 & 405 \\
\hline Pulling Together: A Guide for Curriculum Developers & 8760 & 774 \\
\hline Pulling Together: A Guide for Teachers and Instructors & 2475 & 694 \\
\hline
\end{tabular}

Table 2. Analytics for Pulling Together Indigenization Guides

Leadership at BCcampus continues to reflect on positionality within the post-secondary education system in $\mathrm{BC}$ and to explore dominant colonial organisational traits in order to assess how we build or redefine our relationships with Indigenous communities, advisory committee membership, organisational composition, contractual agreements, job descriptions, approaches to learning and teaching, event keynotes and topics, and expected Indigenised behaviours and actions of staff. I take comfort in the discomfort of the learning journey and accept that it will take time and has no defined end point.

Michelle Glubke is a Polish-Irish American and Canadian. She is an experienced facilitator and leader of innovative, collaborative work in post-secondary education. She resides in Ottawa, Ontario as a new visitor on Algonquin territory. 
1. For a full list of contributors, see https://bccampus. ca/2018/09/06/bccampus-indigenizationprofessional-learning-series/

2. It is unknown how many children died in residential schools as many burials are unmarked. The TRC has documented the deaths of over 4000 residential school students and has indicated that the numbers are probably higher; see http://trc. ca/events-and-projects/missing-children-project. html.

3. Truth and Reconciliation Commission of Canada (TRC), The Truth and Reconciliation Commission Calls to Action (Winnipeg, MB: TRC, 2015), 1, http://trc.ca/assets/pdf/Calls_to_Action_ English2.pdf.

4. Government of British Columbia, Aboriginal Post-secondary Education and Training Policy Framework and Action Plan 2020: Vision for the Future (Victoria, BC: Government of British Columbia, 2019), 13, https://www2.gov.bc.ca/ assets/gov/education/post-secondary-education/ aboriginal-education-training/aboriginal_action_ plan.pdf

5. Early conceptual work to develop a series of guides was completed by Janice Simcoe and Corrine Michel and a team of educators at Camosun College.

6. Dianne Biin, in collaboration with the BCcampus Indigenization Project steering committee. The text is available in the overview section of each guide; see https://opentextbc.ca/indigenizationfoundations/ front-matter/foundations-guide-overview/

7. The University of British Columbia open online course "Reconciliation through Indigenous Education" is available at http://pdce.educ.ubc. $\mathrm{ca} /$ reconciliation/.
8. For the Kairos Blanket Exercise, see https://www. kairosblanketexercise.org.

9. BCcampus, BCcampus Indigenization Project: Environmental Scan Summary, http://solr. bccampus.ca:8001/bcc/file/c0a932f48 d 79 - 4 d 3 d - a 5 d 4 - 3 f 8 c 128 c $0236 / 1 /$ BCcampusIndigenizationSummary.pdf (accessed 6 April 2019).

10. Dianne Biin, in collaboration with the BCcampus Indigenization Project steering committee, Open Professional Learning Resources - Audience Profiles, http://solr.bccampus.ca:8001/bcc/file/ c0a932f4-8d79-4d3d-a5d4-3f8c128c0236/1/ Audience\%20Profiles\%20portrait.pdf (accessed 6 April 2019).

11. The Levels of Indigenizing Working Model is an open model developed during the BCcampus Indigenization Project by Dianne Biin on behalf of the Project steering committee; see http://solr. bccampus.ca:8001/bcc/file/c0a932f4-8d794d3d-a5d4-3f8c128c0236/1/Audience\%20 Profiles\%20portrait.pdf. The 'resisting practice' and 'resisting process' rows of the table were adapted on 12 April 2019 by Janice Simcoe and Dianne Biin.

12. Discussions about the type of knowledge that would be shared were thorough and helped to clarify understandings. There was agreement that no sacred knowledge would be included - rather, knowledge appropriate for the general public. 